Marquette University

\title{
e-Publications@Marquette
}

School of Dentistry Faculty Research and

Publications

Dentistry, School of

$11-2017$

\section{D Printed TCP-Based Scaffold Incorporating VEGF-Loaded PLGA Microspheres for Craniofacial Tissue Engineering}

\author{
Farahnaz Fahimipour \\ Marquette University \\ Morteza Rasoulianboroujeni \\ Marquette University \\ Erfan Dashtimoghadam \\ Marquette University \\ Kimia Khoshroo \\ Marquette University \\ Mohammadreza Tahriri \\ Marquette University
}

See next page for additional authors

Follow this and additional works at: https://epublications.marquette.edu/dentistry_fac

Part of the Dentistry Commons

\section{Recommended Citation}

Fahimipour, Farahnaz; Rasoulianboroujeni, Morteza; Dashtimoghadam, Erfan; Khoshroo, Kimia; Tahriri, Mohammadreza; Lobner, Doug; and Tayebi, Lobat, "3D Printed TCP-Based Scaffold Incorporating VEGFLoaded PLGA Microspheres for Craniofacial Tissue Engineering" (2017). School of Dentistry Faculty Research and Publications. 291.

https://epublications.marquette.edu/dentistry_fac/291 


\section{Authors}

Farahnaz Fahimipour, Morteza Rasoulianboroujeni, Erfan Dashtimoghadam, Kimia Khoshroo, Mohammadreza Tahriri, Doug Lobner, and Lobat Tayebi 
Marquette University

\section{e-Publications@Marquette}

\section{Dentistry Faculty Research and Publications/School of Dentistry}

This paper is NOT THE PUBLISHED VERSION; but the author's final, peer-reviewed manuscript. The published version may be accessed by following the link in the citation below.

Dental Materials, Vol. 33, No. 11 (2017): 1205-1216. DOI. This article is @ Elsevier and permission has been granted for this version to appear in e-Publications@Marquette. Elsevier does not grant permission for this article to be further copied/distributed or hosted elsewhere without the express permission from Elsevier.

\section{D printed TCP-based scaffold incorporating VEGF- loaded PLGA microspheres for craniofacial tissue engineering}

F. Fahimipour

Marquette University School of Dentistry, Milwaukee, WI

M. Rasoulianboroujeni

Marquette University School of Dentistry, Milwaukee, WI

E. Dashtimoghadam

Marquette University School of Dentistry, Milwaukee, WI

K. Khoshroo

Marquette University School of Dentistry, Milwaukee, WI

M. Tahriri

Marquette University School of Dentistry, Milwaukee, WI

F. Bastami

Research Institute of Dental Sciences, School of Dentistry, Shahid Beheshti University of Medical Sciences, Tehran, Iran 


\title{
D. Lobner
}

Department of Biomedical Sciences, Marquette University, Milwaukee, WI

\section{Tayebi}

Marquette University School of Dentistry, Milwaukee, WI

Department of Engineering Science, University of Oxford, Oxford OX1 3PJ, UK

\begin{abstract}
Objective

Vascularization is a critical process during bone regeneration/repair and the lack of tissue vascularization is recognized as a major challenge in applying bone tissue engineering methods for cranial and maxillofacial surgeries. The aim of our study is to fabricate a vascular endothelial growth factor (VEGF)-loaded gelatin/alginate/ $\beta$-TCP composite scaffold by 3D printing method using a computer-assisted design (CAD) model.
\end{abstract}

\section{Methods}

The paste, composed of (VEGF-loaded PLGA)-containing gelatin/alginate/ $\beta$-TCP in water, was loaded into standard Nordson cartridges and promptly employed for printing the scaffolds. Rheological characterization of various gelatin/alginate/ $\beta$-TCP formulations led to an optimized paste as a printable bioink at room temperature.

Results

The in vitro release kinetics of the loaded VEGF revealed that the designed scaffolds fulfill the bioavailability of VEGF required for vascularization in the early stages of tissue regeneration. The results were confirmed by two times increment of proliferation of human umbilical vein endothelial cells (HUVECs) seeded on the scaffolds after 10 days. The compressive modulus of the scaffolds, $98 \pm 11 \mathrm{MPa}$, was found to be in the range of cancellous bone suggesting their potential application for craniofacial tissue engineering. Osteoblast culture on the scaffolds showed that the construct supports cell viability, adhesion and proliferation. It was found that the ALP activity increased over $50 \%$ using VEGF-loaded scaffolds after 2 weeks of culture.

\section{Significance}

The 3D printed gelatin/alginate/ $\beta$-TCP scaffold with slow releasing of VEGF can be considered as a potential candidate for regeneration of craniofacial defects.

\section{Keywords}

3D printing, $\beta$-Tricalcium phosphate, PLGA microsphere, VEGF, Scaffold, Tissue engineering

\section{Introduction}

Critically-sized bone defects created due to infection, tumor resection, or traumatic fractures cannot be healed spontaneously, and external interventions are needed in most cases to regenerate new bone to restore, maintain or improve its function. Although autografts are considered as the gold standard treatment, ${ }^{1}$ it remains challenging for the clinicians to select between autografts, allografts, xenografts or engineered tissues. $2,3,4,5$ The limited access to bone grafts has led to attempts to develop tissue engineering techniques using the three factors of scaffold, growth factors and/or cells for achieving favorable outcomes in bone regeneration. 
Composition and physical properties of the porous scaffold can directly influence the regeneration process; biomimetic scaffolds can yield a more favorable outcome. ${ }^{6,7,8}$ Additive manufacturing (AM) approaches can be used to fabricate scaffolds with tailored pore size and porosity for complex-shaped defects, the fabrication of which is problematic or impossible using other manufacturing methods reported in the literature..$^{9,10,11} 3 \mathrm{D}$ printing/AM allows fabrication of 3D objects of virtually any shape from a computer aided design (CAD). ${ }^{12}$ Two key factors for successful 3D printing fabrication are ink/binder selection and process parameter optimization. The advantage of 3D-printing is the fine control over various features of the scaffold. ${ }^{13}$ Also, one of the widely used techniques of low temperature fused deposition modeling provides mild condition of processing, which allows plotting of drug and biomolecules such as proteins and living cells. ${ }^{14}$ However, there is a significant challenge regarding development of suitable structural materials containing adequate amounts of bioactive components. ${ }^{15}$

Calcium phosphate-based formulations have presented excellent osteoconductivity and biocompatibility in reconstructive surgeries for more than 30 years. ${ }^{11,16,17,18,19,20,21,22,23,24,25}$ Tricalcium phosphate (TCP), as one of the most widely used calcium phosphates in bone tissue engineering, has demonstrated osteogenic properties, phase stability and strong bond formation with the host bone tissue in different studies. ${ }^{26,27,28,29}$ 3D-printed TCP-based scaffolds could be considered as a proper choice for bone tissue engineering applications, since both the fine control over the structure and shape through 3D printing and osteoconductivity of the composition can be exploited. However, when encapsulation and release of sensitive biomolecules such as growth factors is required, high temperature post processes like sintering should be avoided. In this case, biopolymers such as gelatin and alginate might be used both as the binder to facilitate the printing process and as the matrix to incorporate growth factor carriers. Gelatin, a natural polymer obtained from partial hydrolysis of collagen, provides Arg-Gly-Asp (RGD) motifs that can mediate cell attachment via interaction with integrin. ${ }^{30,31,32}$ The sol-gel transition of gelatin can be exploited in 3D printing procedures. On the other hand, alginate, a natural polysaccharide, has been widely used as a biomaterial for bone tissue engineering because of its biocompatibility, non-immunogenicity and biodegradability. ${ }^{33}$ Alginate has been widely used as a thickener in the food industry ${ }^{33}$ and can be used to adjust the viscosity and rheological properties of the ink.

The lack of functional vascularization is a major challenge in the successful clinical approach of bone tissue engineering in the practice of reconstructive orthopedic and craniofacial surgery. ${ }^{34}$ As a result, the aim of bone tissue engineering is not only the culture of osteogenic cells on osteoconductive scaffold, but also the induction of angiogenesis to support the metabolic needs of bone. Although the main VEGF receptors expressed on endothelial cells, there are many VEGF receptors expressed on chondrocytes and osteoblasts. ${ }^{35}$ Consequently VEGF not only promotes angiogenesis but also play an important role in bone growth and repair. ${ }^{36,37}$ Therefore, an osteoconductive scaffold releasing VEGF could be an appropriate candidate for bone regeneration. However, encapsulation and sustained release of fragile biomolecules, such as growth factors, is very challenging. Researchers have increasingly become interested in using biodegradable polymers as host materials for drug delivery systems in the past few decades. These systems not only protect the encapsulated molecule against aggressive environments but also release the molecule in a sustainable manner. Poly (lactic-co-glycolic acid) (PLGA) has been widely used for growth factor sustained delivery in different forms including coating layers and microspheres. ${ }^{38,39,40,41}$ Growth factor loaded PLGA microspheres can be easily incorporated into the ink to be 3D printed. 
The aim of current study was to develop a 3D printed TCP-based scaffold with sustained release of VEGF for bone tissue engineering applications. Gelatin and alginate were employed as the binders to facilitate 3D printing. In fact, we hypothesized that gelatin/alginate/TCP scaffold containing vascular endothelial growth factor (VEGF)-loaded PLGA microspheres, fabricated by 3D plotting according to a predesigned CAD-model, could be a potential candidate for treatment of bone defects.

\section{Experimental procedure}

\subsection{Materials}

$\beta$-TCP, phosphate buffer saline (PBS), Alginate powder and gelatin (Type A, Bloom $300 \mathrm{~g}$ ) were purchased from Sigma-Aldrich, USA. Dichloromethane, $\mathrm{CaCl}_{2}$ and N-hydroxysuccinimide (NHS) were obtained from Alfa Aesar, USA. PLGA was purchased from Corbion Purac, PURASORB ${ }^{\circledR}$ PDLG 5010. HUVECs, Osteoblasts and VEGF were purchased from Cell Applications Inc., USA and finally, N-(3dimethylaminopropyl)- $\mathrm{N}^{\prime}$-ethylcarbodiimide (EDC) was obtained from TCI America, USA. DMEM and FBS were purchased from Sigma. MTT and Alamar blue assays were obtained from Sigma and life technologies, respectively. All materials were utilized as received, without any further purification.

\subsection{Formulating the ink for printing}

In the formulation, $\beta$-TCP and alginate were used as the main component and thickener, respectively. Gelatin was employed as the hardening agent because of its sol-gel transition. Since sol-gel transition temperature of the ink is influenced by gelatin concentration, it plays a key role in printability of the ink. The concentration of $\beta$-TCP and alginate were set at $30 \%(w / v)$ and $5 \%(w / v)$, respectively and the gelatin concentration was altered $(1,3$ and $10 \%(w / v))$. The effect of gelatin concentration on the solgel transition of the ink was then investigated using rheometry. The rheological measurements were performed using a shear rheometer (Kinexus, Malvern, UK) with a stainless steel parallel-plate geometry of $20 \mathrm{~mm}$ in diameter and a Peltier temperature control. The warm paste to be tested was loaded onto the pre-heated Peltier plate $\left(33^{\circ} \mathrm{C}\right)$ of the rheometer and the upper plate was lowered until it gently touched the surface of the sample at a gap distance of $0.3 \mathrm{~mm}$, and excess material was removed.

Frequency sweeps for various formulations were performed at temperatures in decreasing $3{ }^{\circ} \mathrm{C}$ increments ranging from $33^{\circ} \mathrm{C}$ to $9{ }^{\circ} \mathrm{C}$ in order to determine the sol-gel transitions. A constant shear strain of $1 \%$ (angular displacement of $4 \times 10^{-4} \mathrm{rad}$ ) was applied during frequency sweep $(1-15 \mathrm{~Hz}$, logarithmic). All the measurements were carried out within the linear viscoelastic regions.

The formulation with the sol-gel transition temperature closest to room temperature was selected for printing. The viscometry of the selected formulation was performed using the same geometry and gap distance. The shear stress and viscosity were measured at temperatures in decreasing $5{ }^{\circ} \mathrm{C}$ increments ranging from $35^{\circ} \mathrm{C}$ to $15^{\circ} \mathrm{C}$. At each temperature, the rheological evaluation consisted of two consecutive shear cycles with no rotational pre-shear step. The shear rate varied linearly in ramp mode from 0 to $100 \mathrm{~s}^{-1}$ with $10 \mathrm{~s}^{-1}$ intervals in $2 \mathrm{~min}$ and then back to $0 \mathrm{~s}^{-1}$. The total testing time was $12 \mathrm{~min}$.

\subsection{Microsphere loaded ink preparation}

VEGF loaded PLGA microspheres were fabricated through a modified double emulsion-solvent evaporation technique. VEGF was dissolved in sterile PBS (3 $\mu \mathrm{g}$ in $0.2 \mathrm{ml}$ ) mixed with $1 \mathrm{~mL}$ of a $10 \% \mathrm{w} / \mathrm{v}$ PLGA solution in dichloromethane. The first emulsion was obtained through vortexing the mixture for 
$30 \mathrm{~s}$. The resulting emulsion (W/O) was added dropwise into $20 \mathrm{~mL}$ of $3 \%$ aqueous solution of gelatin and stirred at $800 \mathrm{rpm}$ at $30^{\circ} \mathrm{C}$ for $5 \mathrm{~min}$ to produce a double W/O/W emulsion. After $5 \mathrm{~min}$, the stirring speed was reduced to $500 \mathrm{rpm}$, and the solvent was allowed to evaporate at $30{ }^{\circ} \mathrm{C}$ for $3 \mathrm{~h}$. VEGF free PLGA microspheres were produced using the same protocol except blank PBS was used to prepare the first emulsion. In the next step, alginate powder was added to the suspension of microspheres in gelatin aqueous solution and allowed to dissolve to yield the final concentration of $5 \%$ $w / v$. Finally, $\beta$-TCP powder was added and all the components were mixed and defoamed using a centrifugal mixer (Thinky, USA). The final concentration of $\beta$-TCP was adjusted to be $30 \% \mathrm{w} / \mathrm{v}$. The uniform paste obtained was taken for printing.

\subsection{Scaffold preparation}

The paste, composed of gelatin/alginate/ $\beta$-TCP in water, was loaded into standard Nordson cartridges and immediately used for printing the scaffolds.

The scaffolds were fabricated by 3D-printing (3D-Bioplatter EnvisionTEC, Germany). For printing, pressure of 2 bars was applied while the plotting speed was adjusted at $10 \mathrm{~mm} / \mathrm{s}$. Cartridge temperature, platform temperature and needle diameter were $28^{\circ} \mathrm{C}, 10^{\circ} \mathrm{C}$ and $450 \mu \mathrm{m}$, respectively.

The pore geometry of the scaffolds was designed as square. After printing, the scaffolds were transferred into a $50 \mathrm{mM} \mathrm{CaCl}_{2}$ solution and incubated for $1 \mathrm{~h}$ at room temperature to allow crosslinking of alginate, followed by washing with deionized water three times. Afterwards, the scaffolds were transferred into a solution of $9.6 \% \mathrm{w} / \mathrm{v}$ EDC and $0.92 \% \mathrm{w} / \mathrm{v}$ NHS in $70 \% \mathrm{v} / \mathrm{v}$ ethanol and incubated for $2 \mathrm{~h}$ at room temperature for crosslinking of gelatin, followed by rinsing in deionized water and drying at room temperature.

\subsection{Morphology, pore size and porosity}

Morphology of the scaffolds' pores was studied using 3D laser scanning digital microscopy (Olympus LEXT OLS 4000, Japan). The porosity of the scaffolds was measured through a liquid displacement method [42]. Ethanol was selected as the displacement liquid, as it permeates through the scaffolds without swelling or shrinking the matrix. The porosity was determined using the following equation:

$$
\text { porosity }=\frac{W_{2}-W_{1}}{W_{2}-W_{3}} \times 100
$$

where $W_{1}$ is the weight of the sample in air, $W_{2}$ the weight of sample with liquid in pores, and $W_{3}$ the weight of sample suspended in ethanol.

\subsection{Mechanical properties of the scaffold}

The compressive strength and Young's modulus of 3D printed scaffolds $(3.5 \times 2 \mathrm{~mm} \mathrm{D} \times \mathrm{H})$ were tested employing a mechanical testing machine (AGS-X, Shimadzu, Japan) equipped with a $5 \mathrm{kN}$ load cell. The test was performed by compressing the scaffolds in z-direction at a constant rate of $1 \mathrm{~mm} / \mathrm{min}$.

\subsection{Entrapment efficiency}

The amount of VEGF actually loaded within the microspheres was measured after complete degradation of $1 \mathrm{mg}$ of unloaded VEGF-loaded particles in $1 \mathrm{~mL}$ of $0.05 \mathrm{~N} \mathrm{NaOH}$ under stirring. After 
$24 \mathrm{~h}$, the solutions were centrifuged at $5000 \mathrm{rpm}$ at room temperature and the supernatant was analyzed for VEGF content by ELISA kit (Cell Applications Inc., USA). Results are expressed as actual loading (ng encapsulated per mg of microspheres) and encapsulation efficiency (ratio of actual to theoretical loading $\times 100) \pm$ standard deviation of values collected from three different batches.

\subsection{Kinetic of VEGF release}

In vitro release of VEGF from VEGF-loaded scaffolds was evaluated in buffer solution. Briefly, samples (10 mg) were suspended in $1 \mathrm{~mL}$ of phosphate buffered saline $(120 \mathrm{mM} \mathrm{NaCl}, 2.7 \mathrm{mM} \mathrm{KCl}, 10 \mathrm{mM}$ phosphate buffer salts) (PBS) at pH 7.4 previously filtered on $0.22 \mu \mathrm{m}$ sterile filters (Millex1, Millipore, USA) and placed in a shaking incubator at $37^{\circ} \mathrm{C}$. At scheduled time intervals, 1, 2, 3, 5, 7 and 10 days

after incubation, $0.1 \mathrm{ml}$ of the release medium was withdrawn for analysis and replaced with the same volume of fresh filtered medium. Samples were centrifuged at $5000 \mathrm{rpm}$ at room temperature and the supernatant was analyzed for VEGF content via ELISA kit. The concentration of VEGF was calculated as Nano gram per milliliter of the solution.

\subsection{Cell culture and VEGF release effect on bioactivity}

The scaffolds $(5 \times 2 \mathrm{~mm} \mathrm{D} \times \mathrm{H})$ were disinfected by three times immersion in $70 \%$ ethanol and rinsing with PBS for 15 min cycles.

The bioactivity of the VEGF released from the microspheres was examined in vitro by measurement of the proliferative capacity of HUVECs after VEGF treatment. HUVECs were cultured in modified endothelial cell growth medium (Cell Applications, USA). To control the impact of VEGF in the cultures, the media used did not contain VEGF. Experiments were performed with cells from passage 4. In order to assess the endothelial cell proliferation capacity after introduction of VEGF by the scaffolds, the HUVECs were seeded into 24 -well culture plates at a density of $1.25 \times 10^{3}$ cells/well, and scaffolds were placed in an upper chamber by employing transwells $(0.4 \mu \mathrm{m}$ pore size, tissue culture treated polycarbonate membrane Corning, USA). Cells were incubated for 7 or 14 days, with VEGF-free or VEGF-loaded scaffolds, or medium alone as control. Cell proliferation in each experimental group was calculated by utilizing [3-(4,5-dimethylthiazol-2-yl)-1,5-diphenyltetrazulium bromide] (MTT, Sigma, USA) mitochondrial reaction. This assay was based on the ability of live cells to decrease a tetrazuliumbased compound, MTT, to a purplish formazan product.

The results of the experiment were recorded as percentage absorbance relative to control sample [tissue culture polystyrene (TCPS)]. Furthermore, the percentage of HUVEC cell proliferation for certain days ( 7 and 14 ) was calculated using the equation: (mean optical density (OD) of the prepared scaffolds at certain day/mean OD of control sample at 7 th day) $\times 100 .{ }^{43,44,45,46}$

\subsection{Osteoblast proliferation}

The capability of the prepared scaffolds $(n=3)$ to induce cell proliferation was evaluated utilizing normal human osteoblasts (HOB, Cell Applications, USA) by the Alamar blue assay. The scaffolds were disinfected using $70 \%$ ethanol as described. The cells were seeded $\left(1 \times 10^{5} \mathrm{cells} / \mathrm{cm}^{2}\right)$ on the scaffold and cultured for 7 and 14 days. After the incubation period, 10\% Alamar blue was added to the scaffold-call complexes. The optical density of the solution was determined at $570 \mathrm{~nm}$ using a microplate reader (Synergy HTX, BioTek, USA) in order to record the difference between samples and control group. Triplicate samples were analyzed for this experiment. 
The results of the experiment were recorded as percentage absorbance relative to control sample [tissue culture polystyrene (TCPS)]. Furthermore, the percentage of osteoblast cell proliferation for certain days ( 7 and 14 ) was calculated using the equation: (mean optical density (OD) of the prepared scaffolds at certain day/mean OD of control sample at 7 th day) $\times 100.44,45,46$

\subsection{Osteoblast and HUVEC adhesion}

Cell adhesion was evaluated using scanning electron microscopy (SEM, JEOL JSM6510). The osteoblasts or HUVECs were seeded onto the scaffolds and allowed to attach. After $24 \mathrm{~h}$, samples were taken out, washed with phosphate buffered saline (PBS) and fixed using Karnovsky's fixative (composed of Paraformaldehyde-Glutaraldehyde) for $2 \mathrm{~h}$. Samples were rinsed with PBS and post-fixed utilizing $1 \%$ Osmium Tetroxide solution. Sample were rinsed with PBS again and dehydrated employing ascending ethanol series (50, 70, 80, 95 and 100 v/v\%). Finally, the samples were chemically dried using 50 and $100 \mathrm{v} / \mathrm{v} \%$ Hexamethyldisilazane (HMDS, each for $10 \mathrm{~min}$ ) and left at room temperature for complete drying. The imaging was conducted after sputter-coating with gold utilizing secondary electron modes at different magnifications.

\subsection{Alkaline phosphatase activity}

Alkaline phosphatase (ALP) activity $(n=3)$ was assessed utilizing an ALP assay kit (G-Biosciences, St Louis, MO, USA). The media was supplemented with osteoblastic medium one day subsequent to seeding. The cells were digested, collected, and lysed after 7 and 14 days' culture in osteoblastic media. The lysates were reacted with $p$-nitrophenyl phosphate ( $p$-NPP), and the absorbance of $p$ nitrophenol was measured at $405 \mathrm{~nm}$ employing a microplate reader. Cells cultured with osteoblastic medium but not seeded on a scaffold were used as the control.

The results of the experiment were recorded as percentage absorbance relative to control sample [tissue culture polystyrene (TCPS)]. Furthermore, the percentage of ALP activity for certain days was calculated using the equation: (mean optical density (OD) of the prepared scaffolds at certain day/mean OD of control sample at 7 th day) $\times 100 \cdot{ }^{43,44,45,46}$

\subsection{Statistical analysis}

All the computable results were articulated as mean \pm standard deviation (SD), and were analyzed by two-tailed t-test. P-value $<0.05$ was considered to be statistically significant.

\section{Results}

\subsection{Gel point measurement}

A printable ink is required to be fluid and extrudable from the needle while it should be able to maintain its shape once deposited on the platform. To obtain such an ink, gelatin was used as an additive due to its sol-gel transition. One of the difficulties associated with printing such an ink is needle obstruction due to gelation. Since the temperature of the needle used for extrusion is not easily adjustable, the gelatin containing inks may clog the needle during printing procedure if their gel point is above room temperature. The rheological measurements were conducted in this study to assess the gel point of different formulations in order to select the one that represents the closest transition temperature to room temperature. 
The gel point of various formulations was determined using oscillatory sweep measurements. According to the method of Winter and Chambon, ${ }^{47,48}$ the gelation temperature can be defined by observation of a frequency-independent value of damping factor ( $\tan \delta$ ) obtained from a multifrequency plot for a temperature sweep measurement. The gel point denotes the transition of a material from liquid to solid-like behavior (i.e. sol to gel transition). At gel point, the correlation length diverges to infinite size. This appearance of long-range connectivity is most simply observed in a rheological experiment. ${ }^{49}$

Fig. 1 shows Tan (delta) at different frequencies for various formulations as a function of temperature. As can be seen, the gel point increased with increasing gelatin content, which is well consistent with the gelation behavior of gelatin-based solutions. In fact, with decreasing temperature, the coil to helix transition of gelatin chains increases, which is responsible for formation of physical junctions and consequent gelation. ${ }^{50}$ In view of this, with increasing gelatin concentration the entanglement of gelatin chains and percolation of physical junctions is achieved at higher temperature (Table 1). Among the formulations examined, $3 \%$ gelatin was found to have a sol-gel transition temperature very close to the room temperature, making it versatile for printing. Interestingly, the addition of $30 \%$ TCP as the main component of the formulation did not have any significant effect on the sol-gel transition temperature of gelatin-alginate blend solution. Such an observation could be associated with the dominant role of intra- and intermolecular interactions of gelatin chains with alginate rather than TCP particles.
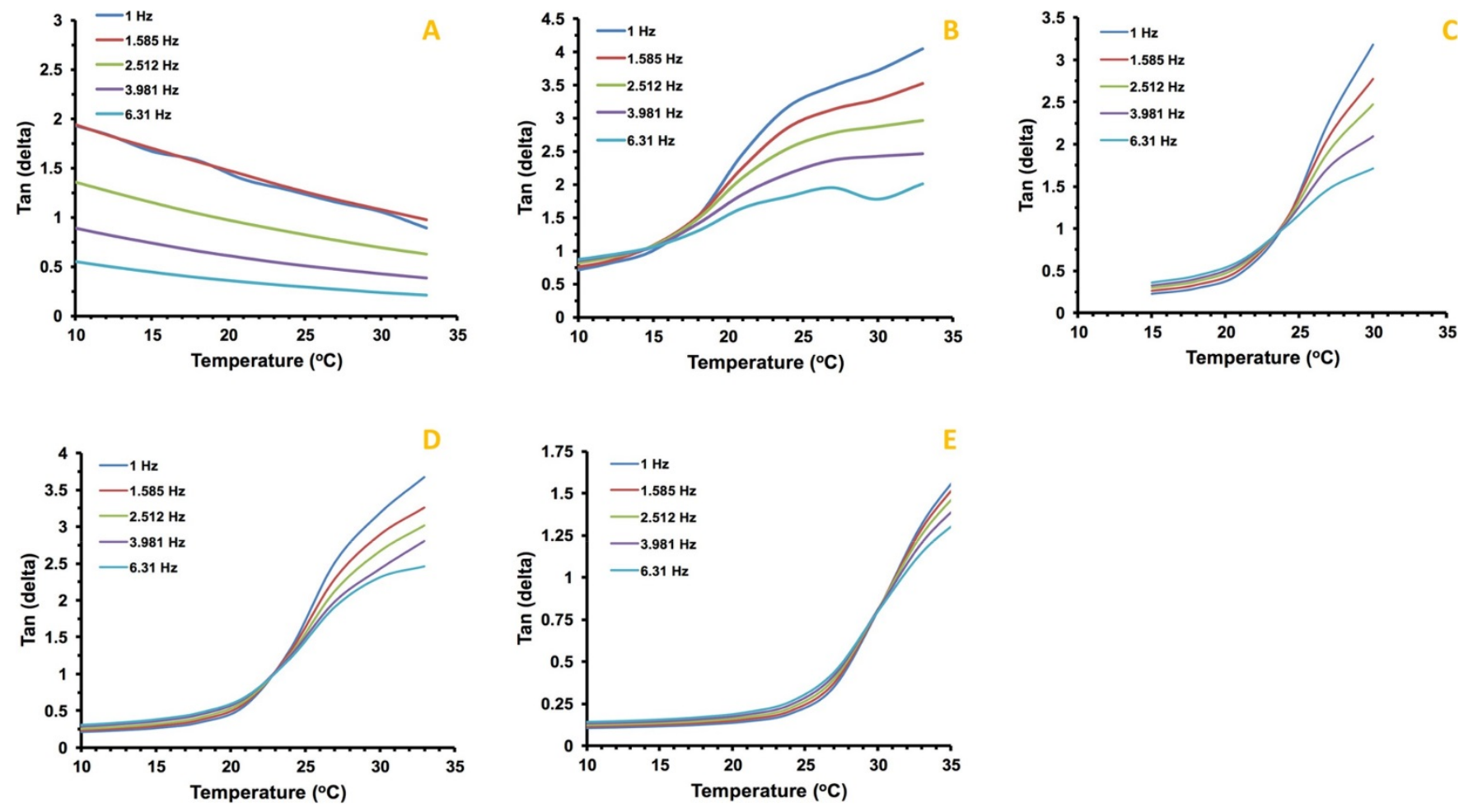

Fig. 1. Tan (delta) at different frequencies for (a) TCP 30\%/ALG 5\%, (b) TCP 30\%/ALG 5\%/GEL 1\%, (c) ALG 5\%/GEL 3\%, (d) TCP 30\%/ALG 5\%/GEL 3\% and (e) TCP 30\%/ALG 5\%/GEL 10\% as function of temperature. 
Table 1. The transition temperatures for various formulations.

\begin{tabular}{|l|l|l|l|}
\hline \% Gelatin & \% Alginate & \% TCP & Gel point $\left(^{\circ} \mathbf{C}\right)$ \\
\hline 0 & 5 & 30 & - \\
\hline 1 & 5 & 30 & 15 \\
\hline 3 & 5 & 30 & 23 \\
\hline 10 & 5 & 30 & 29 \\
\hline 3 & 5 & 0 & 23 \\
\hline
\end{tabular}

\subsection{Viscosity of the selected formulation}

The printability of a paste used as an ink or bio-ink for 3D printing is often a concern. Here, rheological properties of the pastes are believed to play an important role in determining their printability. Therefore, it is worthwhile to study and understand the relationship between 3D printability and rheological properties of the prepared pastes. Viscosity of the optimum paste (Gel/Alg/TCP:3/5/30) at various temperatures is demonstrated in Fig. 2 . As can be seen, viscosity decreased with increasing temperature from $15^{\circ} \mathrm{C}$ to $30^{\circ} \mathrm{C}$. The paste showed shear-thinning behavior at low shear rates but behaved more similar to Newtonian fluids at high shear rates. The high viscosity at $15{ }^{\circ} \mathrm{C}$ and $20{ }^{\circ} \mathrm{C}$ is because the measurements have been conducted below gel point.

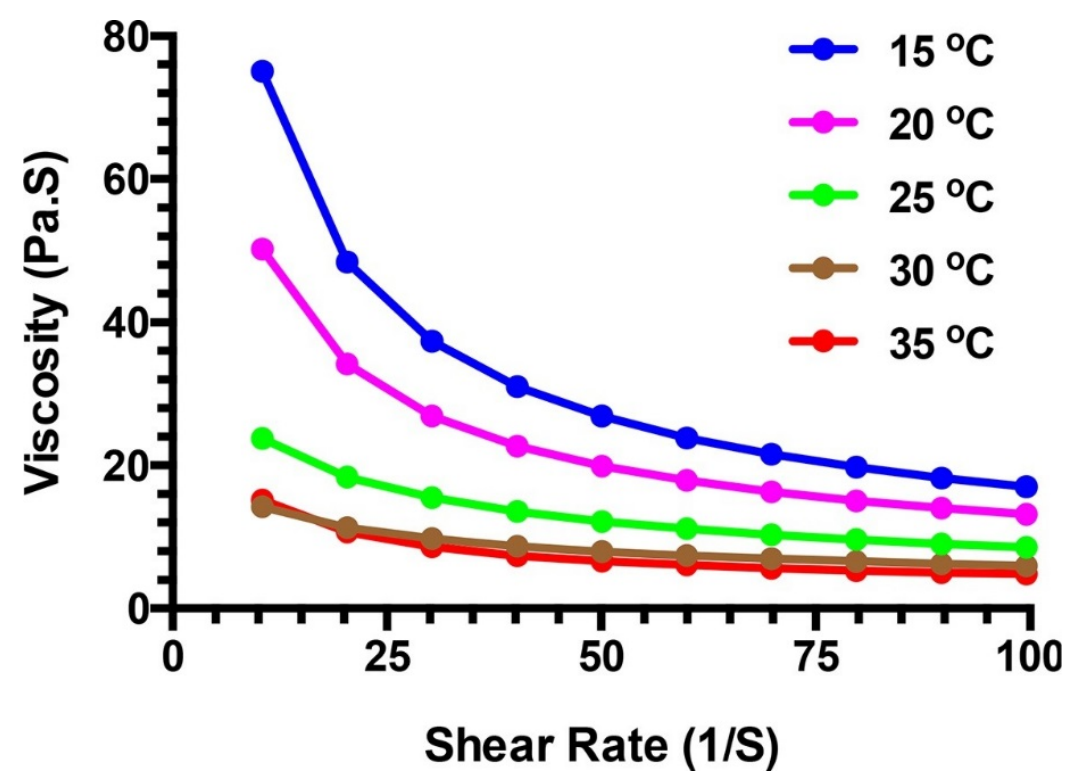

Fig. 2. Viscosity at different temperature as a function of shear rate.

\subsection{Microsphere and scaffolds morphology}

PLGA microspheres were synthesized for sustained release of VEGF (see Fig. 3). The microspheres were spherical with diameters of $138 \pm 39 \mu \mathrm{m}$. The size distribution diagram has been shown in Fig. 3c. 

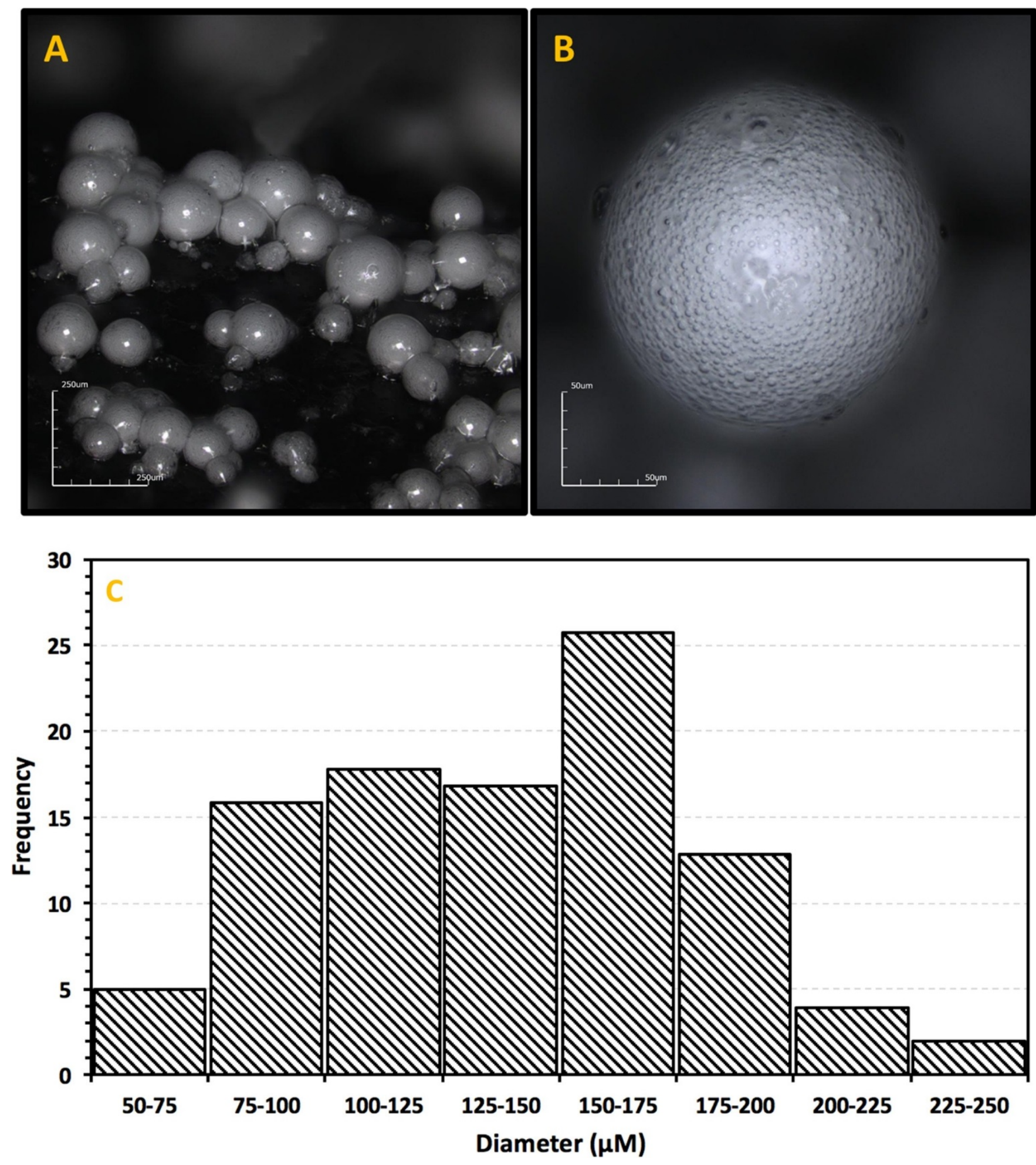

Fig. 3. The morphology of the synthesized PLGA microspheres at (a) low magnification and (b) high magnification and (C) PLGA microspheres diameter distribution.

TCP/alginate/gelatin scaffold containing VEGF loaded PLGA microspheres were fabricated by 3DP method (see Fig. 4). Mean pore size of the scaffold was about $500 \mu \mathrm{M}$. 

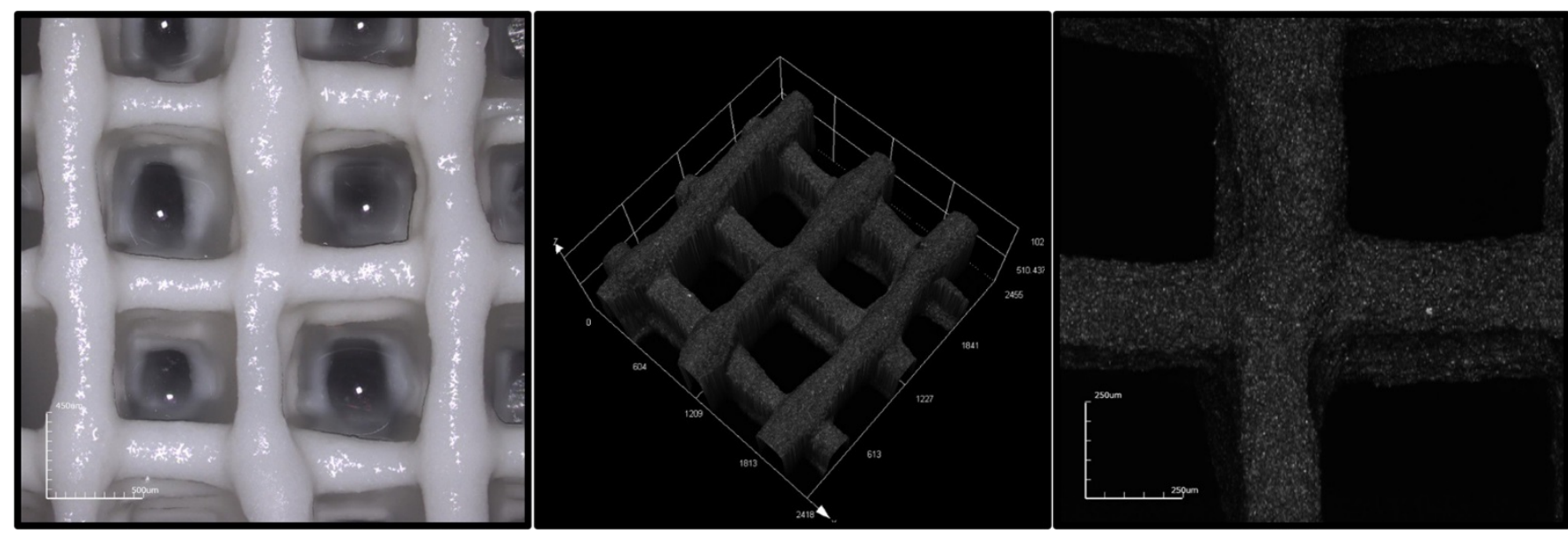

Fig. 4. The morphology of the prepared 3DP scaffold.

\subsection{Porosity and mechanical properties of the scaffolds}

Performance of bone tissue relies on porous 3D scaffold microstructures with particular porosity characteristics that affect the behavior of the ingrown cells. The mechanical properties of 3D porous tissue scaffolds are crucial for their biomechanical tissue engineering applications.

With the aim of examining the effect of porosity on mechanical properties, we have evaluated the load limits for the five scaffolds. Young's modulus was calculated by assessing the slope of the stress-strain curve along the elastic portion of the deformation. The porosity of the prepared 3D printed scaffold was $73.42 \pm 8.4 \%$, while Young's modulus of the scaffold was calculated as $98.31 \pm 10.21 \mathrm{MPa}$.

\subsection{Encapsulation efficiency, release profile and biological activity of VEGF} The entrapment efficiency $(E E)$ is one of the very important physicochemical properties of drug/growth factor-loaded polymeric microspheres. We computed mass of extract in the supernatant by employing a standard curve and then computing entrapment efficiency: $E E \%=67 \%$.

An important characteristic of microspheres is their high stacking limit of medication. The loading of the drug/growth factor into microspheres is obtained by the two following methods: (1) incorporation of the drug/growth factor into the matrix of microspheres during production or, (2) immersion or adsorption of the drug/growth factor onto the surface of the preformed microspheres. ${ }^{51}$

The VEGF encapsulated and released from the PLGA microspheres and entrapped into the scaffold showed favorable outcome to preserve its biological activity in vitro (see Fig. 5). 


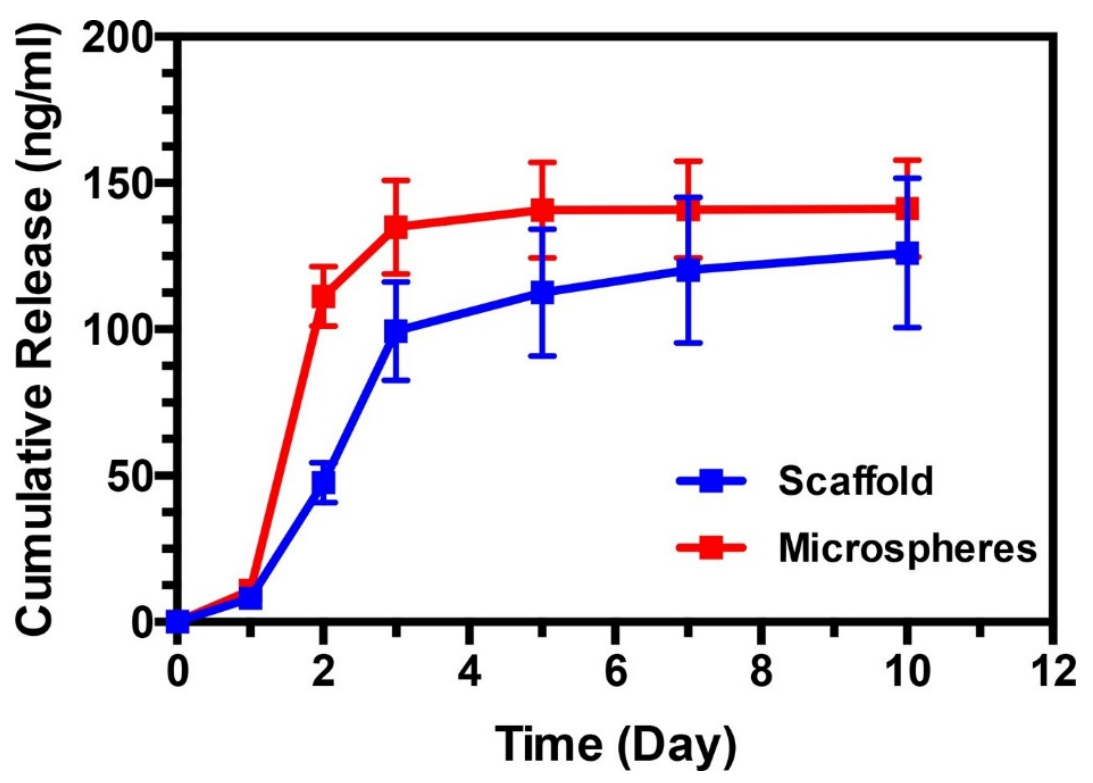

Fig. 5. In vitro release profile of VEGF from PLGA microspheres and 3DP scaffold as a function time.

Drug/growth factor release from biodegradable polymeric microspheres happen through a combination of numerous mechanisms. It generally occurs through desorption of a surface-bound drug/growth factor, diffusion of the drug/growth factor through the polymer matrix, and erosion of the polymeric microspheres. ${ }^{52}$

It is noticeable that the rate of VEGF release will be certainly affected by the microspheres' size. For a given rate of VEGF diffusion, the rate of VEGF efflux per mass of formulation increases as the particle size decreases due to the increase of surface area to volume ratio. In addition, quicker water penetration into the smaller particles and faster degradation of such particles due to higher surface area to volume ratio can increase the release rate..$^{53}$

As observed in Fig. 5, the microsphere formulation showed a biphasic pattern of growth factor release, an initial burst effect because of the immediate release of the surface-connected growth factor and prolonged release in the second stage due to the slow diffusion of the growth factor from the nanoparticle matrix. The fraction released during the first 3 days could be attributed to the fractions of the free growth factor that was released from the PLGA microspheres.

MTT assay showed that the scaffold containing VEGF significantly increased the proliferation rate of HUVECs after 10 days compared to both control and blank scaffold $(P<0.05)$ (Fig. 6). 


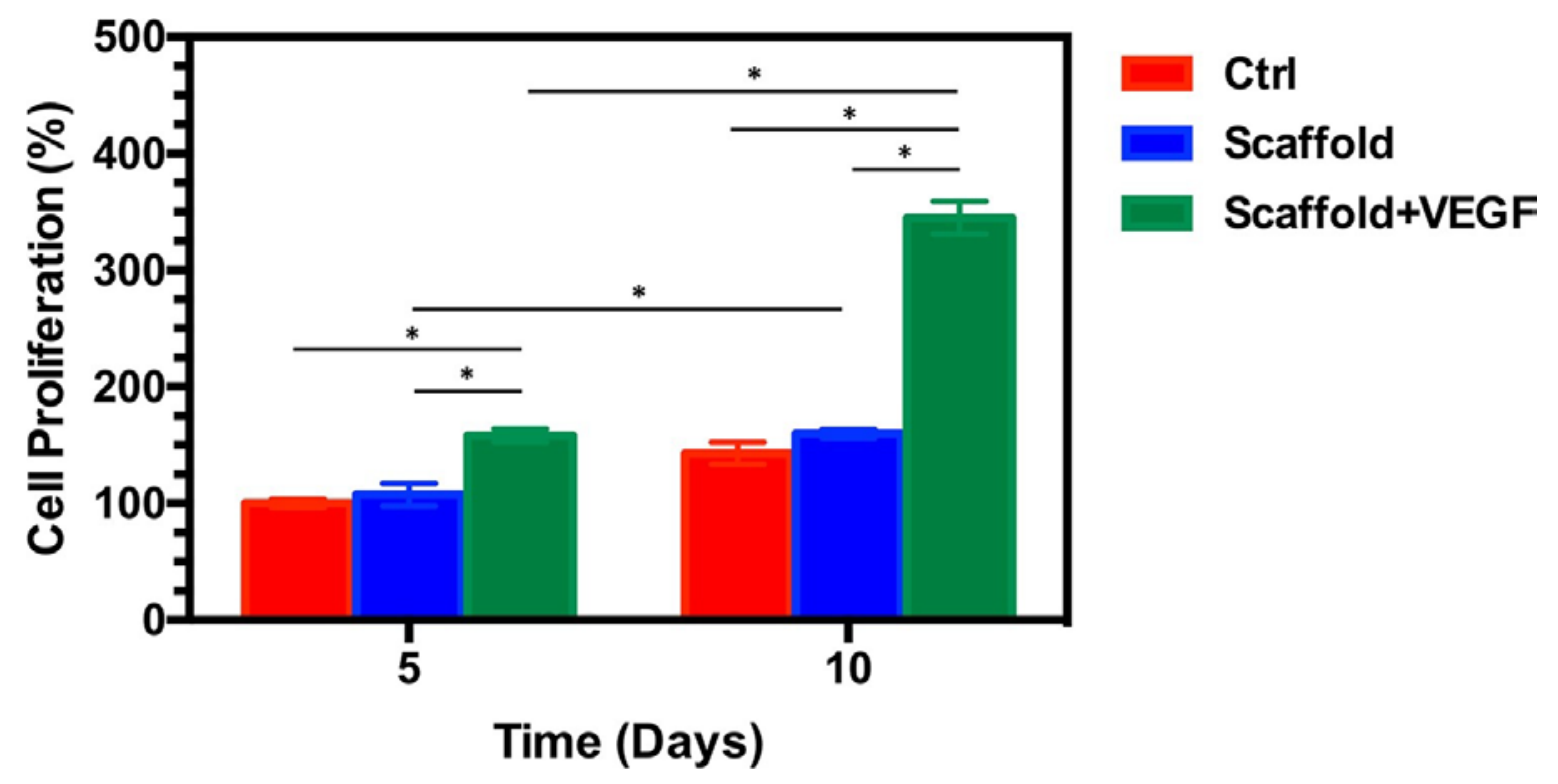

Fig. 6. Proliferation of HUVECs cells on the 3DP scaffolds along with negative control at day 5 and 10 by MTT assay (* $P$ value $<0.05$ ).

\subsection{Osteoblast proliferation}

Osteoblast proliferation rate on the scaffolds was studied by Alamar blue after 7 and 14 days (Fig. 7). The results showed progressive proliferation.
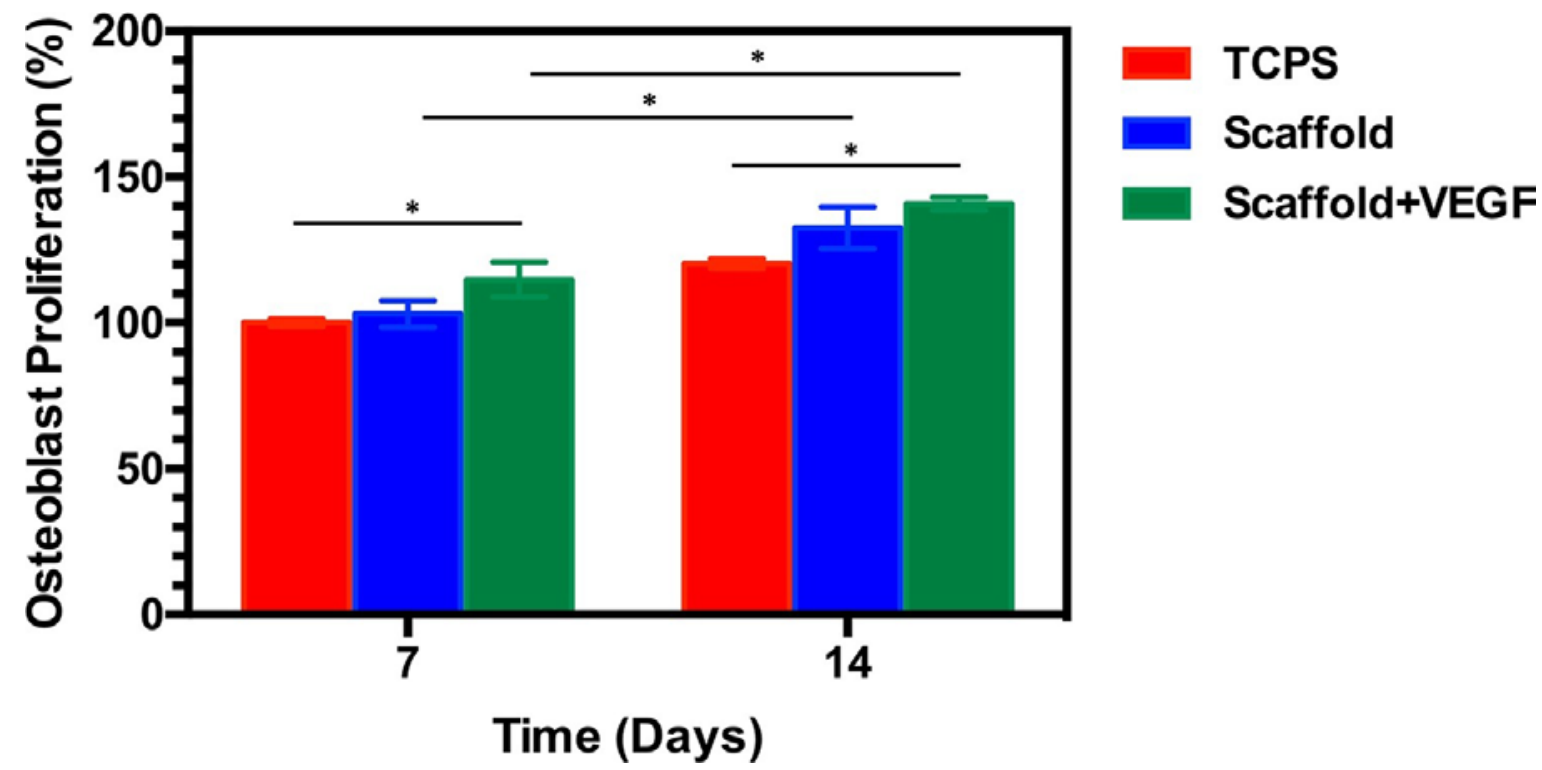

Fig. 7. Proliferation of osteoblast cells on the 3DP scaffolds along with negative control at day 7 and 14 (* $P$ value $<0.05)$

As a living system, the new bone formation is considerably influenced by the surrounding environment. The structure of scaffolds, including morphology, pore size and porosity can affect the cellular behavior. The results demonstrated that osteoblasts were sensitive to the substrate i.e. tissue culture plate or the scaffold. 


\subsection{Osteoblast and HUVEC adhesion}

As observed in Fig. 8(A, B), the osteoblasts have been attached to the surface of the scaffold with their multiple cell processes branching from one side of the pore to another forming an adherent plexus all over the scaffold. It could be vividly seen that osteoblasts have anchored their cytoskeletal projections to cover the surface of the scaffold indicating bioactive topography of the surface of it. Scaffolds also represented excellent HUVEC attachment as seen in Fig. 8(C, D). Presence of both gelatin and $\beta$-TCP in the formulation promotes the cell propagations all over the construct. Gelatin presents Arg-Gly-Asp (RGD) motifs that could mediate cell attachment via interaction with integrin. ${ }^{30}$
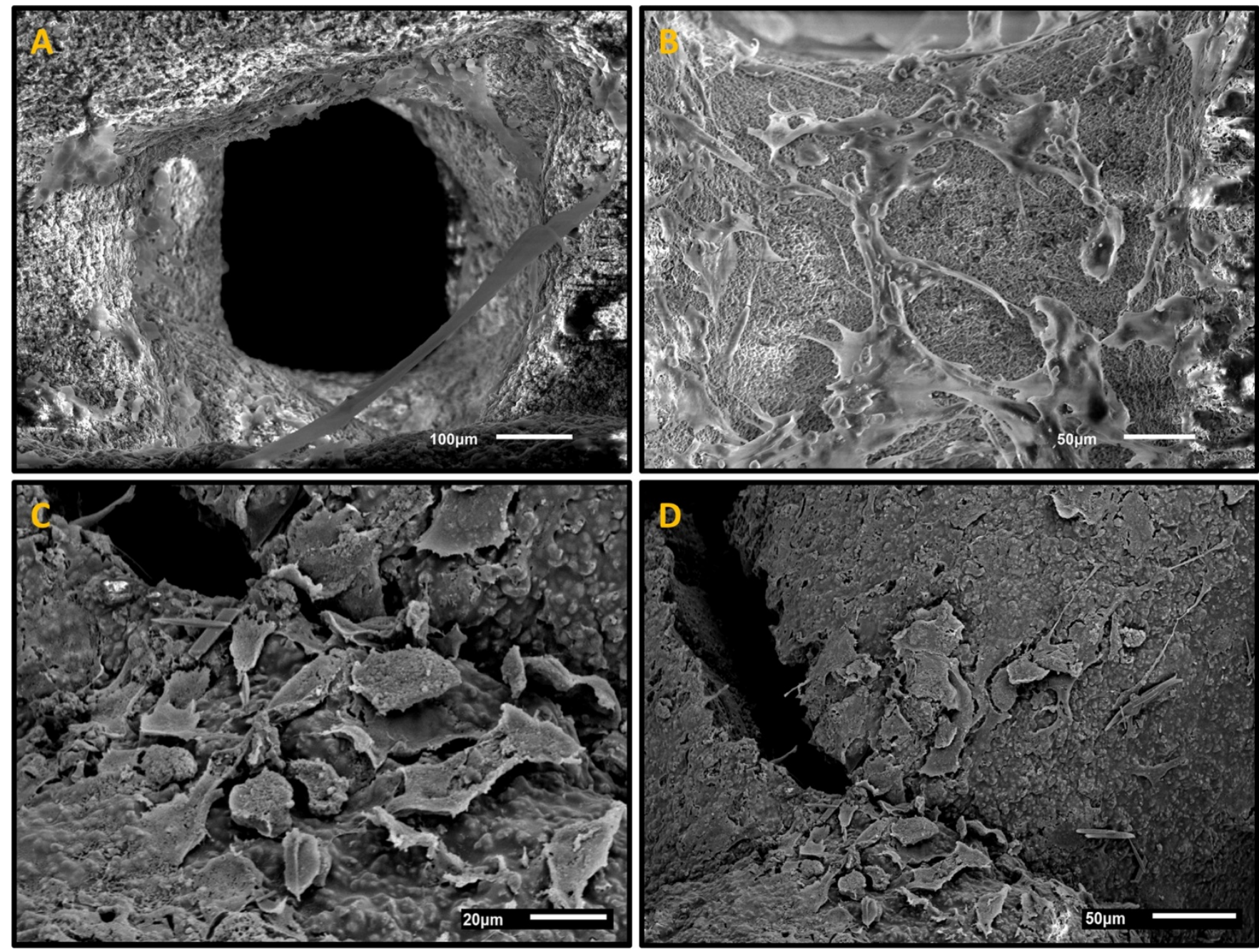

Fig. 8. SEM images of the cells attached on the 3D-printed scaffolds (a) osteoblast (high magnification), (b) osteoblast (low magnification), (c) HUVEC (high magnification) and (d) HUVEC (low magnification).

\subsection{ALP activity}

The effect of VEGF release from the scaffold on bone regeneration was measured by ALP activity after 7 and 14 days (Fig. 9). ALP activity of the Scaffold containing VEGF was significantly greater compared to both control and blank scaffold at both time intervals $(P<0.05)$. This may be attributed to the release of calcium and phosphate ions from $\beta$-TCP and also the presence of VEGF. However, ALP activity was not significantly increased from 7 to 14 days. 


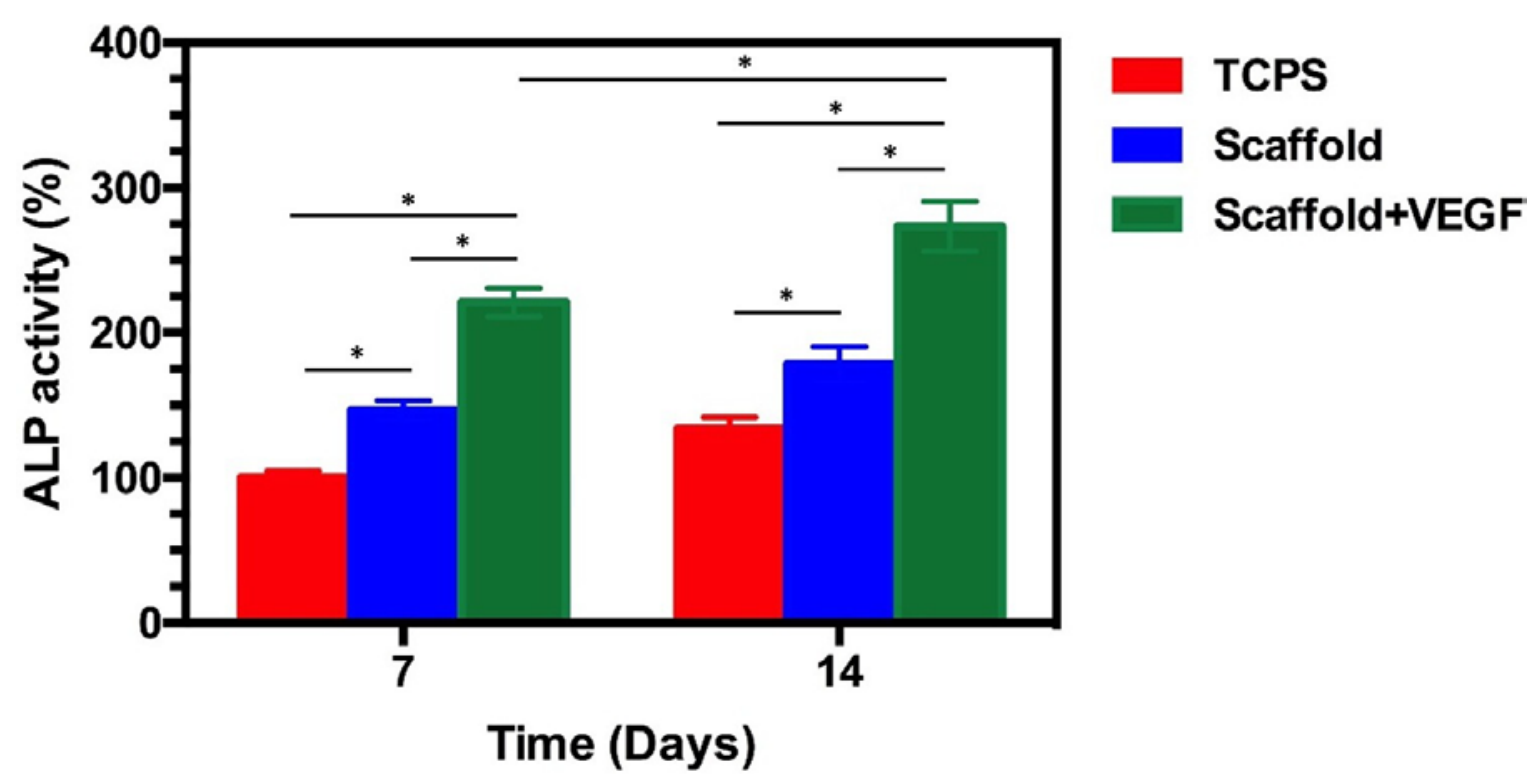

Fig. 9. ALP activity for cells proliferated on the 3D printed scaffolds along with negative control at day 7 and 14 (* $P$ value $<0.05)$.

\section{Discussion}

Spontaneous regeneration of critical-sized bone defects fail in most cases by the endogenous healing response. ${ }^{54}$ Many conventional strategies, including implantation of pre-fabricated constructs or designing delivery systems of growth factors, have been investigated with the aim of improving the healing process. ${ }^{55,56}$ However, there are still challenges in fabrication of an ideal scaffold with proper composition, physical structure and ability of controlled release of growth factors for bone tissue engineering. In the current study, we successfully fabricated a biomimetic porous TCP/alginate/gelatin scaffold containing PLGA microspheres for slow release of VEGF. The printable ink was selected based on the gel point of different formulations of TCP/alginate/gelatin. Adjusting the gel point closer to room temperature makes the ink printable. Although the temperature of the cartridge could be adjusted to higher temperatures, the temperature of the needle is close to room temperature because of its contact with air. If the sol-gel transition occurs above room temperature, the needle will be frequently blocked throughout the printing. On the other hand, very low sol-gel transition temperature results in difficulty of solidifying material on the platform to hold the scaffold shape and reduce the control over scaffold's architecture because of ink flow. In the next step, VEGF was efficiently entrapped into PLGA microspheres, thereby into the structure of the scaffold, and sustained release of VEGF successfully increased proliferation rate of HUVECs. In addition, VEGF released from the scaffold demonstrated significant enhancement of ALP activity and similar viability of osteoblasts compared to the controls.

Hybrid scaffold fabrication strategies are based on having benefit from properties of different biomaterials. ${ }^{57}$ Duan et al. improved the physical and biological properties of bio-printed alginate hydrogel combined with gelatin. ${ }^{58}$ Also, favorable biological properties of alginate/gelatin hydrogels for bone tissue engineering has been reported by Rottensteiner et al. ${ }^{59}$ In fact, a number of drawbacks are known for pure alginate, including low promotion of cell adhesion and slow and uncontrolled degradation kinetics in physiological conditions. ${ }^{60,61}$ Sarker et al. overcame these drawbacks by fabrication of crosslinked alginate/gelatin hydrogel. ${ }^{62}$ Indeed, thickening properties of alginate along with cell adhesion and sol-gel transition of gelatin was exploited in this study to fabricate a TCP-based 
scaffold that showed favorable physical and biological results for bone tissue engineering. In a recent study, Komlev et al. demonstrated the compressive strength of TCP/alginate/gelatin scaffold was enhanced when the percentage of TCP was increased in the structure of the scaffold. ${ }^{63}$ In our study, the fabricated pastes could be handled into designed 3D structures at room temperature $\left(25^{\circ} \mathrm{C}\right)$. Then, the prepared scaffolds were crosslinked with $\mathrm{Ca} 2+$ ions (effective for alginate) and the carbodiimide EDC/NHS (effective for gelatin) for creating the stable scaffolds. Mechanical testing ascertained that the printed composite scaffolds had a strength and modulus in the range of natural bone. The Young's modulus of human natural bone has been reported to be 100-400 MPa by the compression test. ${ }^{64}$

It is known that biomimetic porous scaffolds with interconnected porosity play an essential role in bone tissue engineering. ${ }^{7}$ 3D scaffolds provide a template for cell adhesion and extracellular matrix formation. 3DP method gives the possibility of having 3D scaffold with controlled and interconnected porosity. ${ }^{9}$ Both size and shape of the macro-pore are the key structural factors for bone ingrowth. Although the minimum pore size needed for bone ingrowth still remain a challenging issue, a value of 75-100 $\mu \mathrm{m}$ has been reported by many researchers. ${ }^{65}$ However, it has been shown that osteogenesis could be enhanced with pore sizes larger than $300 \mu \mathrm{m} .{ }^{66}$ By studying the effects of pore size of 3DP TCP scaffolds on human fetal osteoblasts, it has been demonstrated that proliferation rate of cells increases with decrease in designed pore size from 1000 to 750 and $500 \mu \mathrm{m} .{ }^{67}$ In our study, the mean pore size and porosity of the scaffold were about $500 \mu \mathrm{m}$ and $73 \%$, respectively, which were in a desirable range for bone tissue engineering.

It has been confirmed that VEGF, bone morphogenetic proteins (BMPs) and insulin-like growth factor (IGF) play a pivotal role during the natural tissue healing process specially in bone regeneration..$^{2,68}$ In fact, these growth factors have important effects on regulation of cellular activities and initiation of osteogenic differentiation of mesenchymal stem cells, thereby promoting osteogenesis. ${ }^{69}$ In the current study, we demonstrated that VEGF released from the scaffold could significantly enhance the proliferation rate of HUVECs. It is obvious that the concentration of VEGF plays a critical role in the nature and persistence of vasculature formed in a tissue regenerative scaffold. It has been reported that while a low dosage delivery of VEGF is insufficient to generate an increase in angiogenesis at 10 days, higher concentrations can elevate vascularity. Interestingly, while very high dosages generate a more extreme increase than the medium dosage at 10 days, the vessel growth under such treatment is transient and dramatic regression of the neovascularization starts after a while. On the other hand, medium dosage administration has been observed to result in a persistent, elevated and functional vascularity within the scaffold months after VEGF delivery was terminated. ${ }^{70}$ Besides, sustained release of VEGF through PLGA microspheres has been reported to improve vasculogenesis and tissue remodeling compared to free VEGF administration. ${ }^{71}$ The response to the high and medium dosage would suggest that the burst release of the microspheres followed by a moderate sustained release like the release profile obtained in this study can be advantageous for vascularization. Moreover, the impact of VEGF on the bone healing process is well known. ${ }^{72}$ In addition to vessel formation, endochondral and intramembranous ossification in bone growth could be also influenced by VEGF as it plays an important role in the recruitment, survival and activity of bone forming cells. It has been reported that VEGF might directly stimulates migration and differentiation of primary human osteoblasts. ${ }^{73,74}$ In fact, VEGF has valuable effects on the regeneration of critical-size bone defects. We assessed ALP activity as a marker of osteoblastic activity after 7 and 14 days. Significant ALP activity with slow release of VEGF from the scaffold was observed after both 7 and 14 days compared to the controls. High levels of ALP is normally expressed at the end of cell proliferation and during the 
maturation period. ${ }^{75,76}$ VEGF expression lead to an upregulation of BMP-2 and plays an important role in bone growth and repair in addition to its main role of vascularization. ${ }^{19}$

Researchers have been attracted to the localized delivery of growth factors and drugs due to the potential for dose reduction, the reduced side effects compared to systemic delivery and the controlled and sustained release pattern. ${ }^{77}$ Pore size, interconnectivity and geometry of scaffolds can also influence drug loading and control over release rate in vivo. ${ }^{78}$ In addition, biodegradability of the drug carrier plays a crucial role in drug release. PLGA is the most popular biodegradable polymer due to its desirable degradation characteristics, extensive clinical applications and possibilities for controlled drug delivery. PLGA microspheres have been considered as an excellent candidate for growth factor delivery due not only to its desirable sustained release outcomes, but also its favorable physicochemical properties and pharmacokinetic and biodistribution profile. ${ }^{79}$ The drug release profile of PLGA-based carriers demonstrates a biphasic pattern with initial burst release followed by a zero order release. ${ }^{80,81}$ VEGF release from our construct also showed rapid release up to the 3rd day, after which it reached a plateau. Initial burst release of VEGF may be a result of interaction between protein chains on the surface and the medium, dissolution of superficial proteins, as well as water penetration into polymer matrix of the scaffold. ${ }^{79}$ However, the release rate in the initial phase was slower than that of reported for PLGA microspheres in the literature 82 potentially because of incorporation of microspheres in a polymeric matrix. In fact, the construct can be considered as a favorable delivery system for sustained release of VEGF.

In summary, in the current study, we demonstrated favorable sustained release of VEGF loaded into PLGA microspheres entrapped into the structure of the 3DP scaffold for bone tissue engineering. Therefore, the proposed scaffold model can be recommended for delivering other growth factors such as BMPs and IGF for future investigations.

\section{Conclusion}

The 3DP gelatin/alginate/ $\beta$ TCP scaffold with VEGF delivery system consisting of PLGA microspheres, as described in this study, could be considered as a framework with favorable mechanical and biological features supporting cell viability and increasing ALP activity necessary for bone tissue regeneration. Entrapment of PLGA microspheres into the structure of the scaffold may be introduced as an efficient model for drug delivery from 3DP scaffolds for bone tissue engineering to enhance bone regeneration in accord with the degradation of the scaffold in critical-sized bone defects.

\section{Acknowledgement}

The authors would like to acknowledge the NIH/NIDCR grant DE018250 for financial support of the study.

\section{References}

${ }^{1}$ B. Antebi, L. Zhang, D. Sheyn, G. Pelled, X. Zhang, Z. Gazit, et al. Controlling arteriogenesis and mast cells are central to bioengineering solutions for critical bone defect repair using allografts. Bioengineering, 3 (1) (2016), p. 6.

${ }^{2} \mathrm{~F}$. Bastami, A. Khojasteh. Use of leukocyte-and platelet-rich fibrin for bone regeneration: a systematic review. Regener Reconstr Restor, 1 (2) (2016), pp. 47-68. 
${ }^{3}$ M.S.K. Chong, C. Bao, K.P. Ng, J. Lim, J.K.Y. Chan. Human bone xenografts: from preclinical testing for regenerative medicine to modeling of diseases. Curr Mol Biol Rep, 2 (3) (2016), pp. 158-170.

${ }^{4}$ C.M. Misch. Autogenous bone: is it still the gold standard? Implant Dent, 19 (5) (2010), p. 361.

${ }^{5}$ Y. Kim, H. Nowzari, S.K. Rich. Risk of prion disease transmission through bovine-derived bone substitutes: a systematic review. Clin Implant Dent Relat Res, 15 (5) (2013), pp. 645-653.

${ }^{6} \mathrm{M}$. Salehi, F. Bastami. Characterization of eet-electrospun poly ( $\varepsilon$-caprolactone)/poly (I-lactic) acid with calcium phosphates coated with chitosan for bone engineering. Regener Reconstr Restor, 1 (2) (2016), pp. 69-74.

${ }^{7} \mathrm{~S}$. Wu, X. Liu, K.W. Yeung, C. Liu, X. Yang. Biomimetic porous scaffolds for bone tissue engineering. Mater Sci Eng R: Rep, 80 (2014), pp. 1-36.

8J. Sanz-Herrera, J. García-Aznar, M. Doblaré. On scaffold designing for bone regeneration: a computational multiscale approach. Acta Biomater, 5 (1) (2009), pp. 219-229.

${ }^{9}$ S. Bose, S. Vahabzadeh, A. Bandyopadhyay. Bone tissue engineering using 3D printing. Mater Today, 16 (12) (2013), pp. 496-504.

${ }^{10} \mathrm{H}$. Jazayeri, E. Dashtimoghadam, M. Rasoulianbroujeni, M. Bures, L. Tayebi. 3-D printed $\mathrm{PCL} /$ halloysite scaffolds for craniomaxillofacial bone regeneration. Dent Mater, 32 (2016), p. e57.

${ }^{11} \mathrm{~K}$. Khoshroo, T. Almela, M. Tahriri, F. Fahimipour, Z. Metalwala, K. Moharamzadeh, et al. 3D-printing of porous calcium phosphate cements for bone tissue engineering. Dent Mater, 32 (2016), pp. e56-e57.

${ }^{12}$ S.C. Cox, J.A. Thornby, G.J. Gibbons, M.A. Williams, K.K. Mallick. 3D printing of porous hydroxyapatite scaffolds intended for use in bone tissue engineering applications. Mater Sci Eng: C, 47 (2015), pp. 237-247.

${ }^{13}$ R. Detsch, S. Schaefer, U. Deisinger, G. Ziegler, H. Seitz, B. Leukers. In vitro-osteoclastic activity studies on surfaces of 3D printed calcium phosphate scaffolds. J Biomater Appl (2010).

${ }^{14}$ Y. Luo, C. Wu, A. Lode, M. Gelinsky. Hierarchical mesoporous bioactive glass/alginate composite scaffolds fabricated by three-dimensional plotting for bone tissue engineering. Biofabrication, 5 (1) (2012), p. 015005.

${ }^{15}$ S.E. Moulton, G.G. Wallace. 3-Dimensional (3D) fabricated polymer based drug delivery systems. J Control Release, 193 (2014), pp. 27-34.

${ }^{16} \mathrm{~F}$. Fahimipour, T.J. Kashi, K. Khoshroo, E. Dashtimoghadam, M. Rasoulianborujeji, L. Tayebi. 3Dprinted $\beta$-TCP/collagen scaffolds for bone tissue engineering. Dent Mater, 32 (2016), p. e57.

${ }^{17}$ H.E. Jazayeri, M. Tahriri, M. Razavi, K. Khoshroo, F. Fahimipour, E. Dashtimoghadam, et al. A current overview of materials and strategies for potential use in maxillofacial tissue regeneration. Mater Sci Eng: C, 70 (2017), pp. 913-929.

${ }^{18}$ A. Khojasteh, F. Fahimipour, M. Jafarian, D. Sharifi, S. Jahangir, F. Khayyatan, et al. Bone engineering in dog mandible: coculturing mesenchymal stem cells with endothelial progenitor cells in a composite scaffold containing vascular endothelial growth factor. J Biomed Mater Res B Appl Biomater (2016).

${ }^{19}$ A. Khojasteh, F. Fahimipour, M.B. Eslaminejad, M. Jafarian, S. Jahangir, F. Bastami, et al. Development of PLGA-coated $\beta$-TCP scaffolds containing VEGF for bone tissue engineering. Mater Sci Eng: $\mathrm{C}$, 69 (2016), pp. 780-788.

${ }^{20}$ D. Bizari, F. Moztarzadeh, M. Rabiee, M. Tahriri, F. Banafatizadeh, A. Ansari, et al. Development of biphasic hydroxyapatite/dicalcium phosphate dihydrate (DCPD) bone graft using polyurethane foam template: in vitro and in vivo study. Adv Appl Ceram, 110 (7) (2011), pp. 417-425. 
${ }^{21}$ D. Bizari, F. Moztazradeh, M. Fahmy, M. Tahriri, L. Tayebi. Hydroxyapatite/dicalcium phosphate dihydrate composite for dental bone defect repair. Dent Mater, 32 (2016), p. e56.

${ }^{22}$ R. Masaeli, T.J. Kashi, W. Yao, K. Khoshroo, M. Tahriri, L. Tayebi. Preparation of strontium-containing calcium phosphate cements for maxillofacial bone regeneration. Dent Mater, 32 (2016), p. e49.

${ }^{23}$ M. Haghbin-Nazarpak, F. Moztarzadeh, M. Solati-Hashjin, M. Tahriri, K. Khoshroo. Injectable and bioresorbable calcium phosphate delivery system with gentamicin sulphate for treatment of bone diseases: in vitro study. Adv Appl Ceram, 110 (8) (2011), pp. 482-489.

${ }^{24}$ H. Eslami, M. Solati-Hashjin, M. Tahriri, F. Bakhshi. Synthesis and characterization of nanocrystalline hydroxyapatite obtained by the wet chemical technique. Mat Sci Poland, 28 (1) (2010), pp. 513.

${ }^{25} \mathrm{M}$. Rezvannia, F. Moztarzadeh, M. Tahriri. Formation of hydroxyapatite nanoneedles on the surface of a novel calcium phosphate/blood plasma proteins biocement in simulated body fluid (SBF). $J$ Ceram Process Res, 10 (5) (2009), pp. 669-673.

${ }^{26}$ K.-D. Park, Y.-S. Jung, K.-K. Lee, H.-J. Park. Behavior of osteoblast-like cells on a $\beta$-tricalcium phosphate synthetic scaffold coated with calcium phosphate and magnesium. J Craniofac Surg, 27 (4) (2016), pp. 898-903.

${ }^{27}$ C. del Rosario, M. Rodríguez-Évora, R. Reyes, A. Delgado, C. Évora. BMP-2, PDGF-BB, and bone marrow mesenchymal cells in a macroporous $\beta$-TCP scaffold for critical-size bone defect repair in rats. Biomed Mater, 10 (4) (2015), p. 045008.

${ }^{28}$ Y. Yang, J. Wu, G. Jin, L. Li, Z. Li, C. Li. Research of osteoblastic induced rat bone marrow mesenchymal stem cells cultured on $\beta$-TCP/PLLA porous scaffold. Int J Clin Exp Med, 8 (3) (2015), pp. 32023209.

${ }^{29}$ F.F.M. Mojahedian, K.L. Larsen, M. Kalantar, F. Bastami, N. Omatali. Ethanol-based sol-gel synthesis of nano-crystalline hydroxyapatite with different calcium phosphorus ratios ( $\mathrm{Ca} / \mathrm{P})$. J Ceram Process Res, 17 (11) (2016), pp. 1138-1142.

${ }^{30}$ A.K. Teotia, A. Gupta, D.B. Raina, L. Lidgren, A. Kumar. Gelatin-modified bone substitute with bioactive molecules enhance cellular interactions and bone regeneration. ACS Appl Mater Interfaces, 8 (17) (2016), pp. 10775-10787.

${ }^{31}$ M. Kabiri, S.H. Emami, M. Rafinia, M. Tahriri. Preparation and characterization of absorbable hemostat crosslinked gelatin sponges for surgical applications. Curr Appl Phys, 11 (3) (2011), pp. 457-461.

${ }^{32}$ M. Mozafari, F. Moztarzadeh, M. Rabiee, M. Azami, N. Nezafati, Z. Moztarzadeh, et al. Development of 3D bioactive nanocomposite scaffolds made from gelatin and nano bioactive glass for biomedical applications. Adv Compos Lett, 19 (2) (2010), pp. 91-96.

${ }^{33}$ J. Venkatesan, I. Bhatnagar, P. Manivasagan, K.-H. Kang, S.-K. Kim. Alginate composites for bone tissue engineering: a review. Int J Biol Macromol, 72 (2015), pp. 269-281.

${ }^{34}$ C.O. Cassell, O.S. Hofer, W.A. Morrison, K.R. Knight. Vascularisation of tissue-engineered grafts: the regulation of angiogenesis in reconstructive surgery and in disease states. Br J Plast Surg, 55 (8) (2002), pp. 603-610.

${ }^{35}$ N. Ferrara, H.-P. Gerber, J. LeCouter. The biology of VEGF and its receptors. Nat Med, 9 (6) (2003), pp. 669-676.

${ }^{36}$ E. Zelzer, W. McLean, Y.-S. Ng, N. Fukai, A.M. Reginato, S. Lovejoy, et al. Skeletal defects in VEGF120/120 mice reveal multiple roles for VEGF in skeletogenesis. Development, 129 (8) (2002), pp. 1893-1904. 
${ }^{37}$ H.-P. Gerber, T.H. Vu, A.M. Ryan, J. Kowalski, Z. Werb, N. Ferrara. VEGF couples hypertrophic cartilage remodeling, ossification and angiogenesis during endochondral bone formation. Nat Med, 5 (6) (1999), pp. 623-628.

${ }^{38}$ A. Khojasteh, F. Fahimipour, M.B. Eslaminejad, M. Jafarian, S. Jahangir, F. Bastami, et al. Development of PLGA-coated $\beta$-TCP scaffolds containing VEGF for bone tissue engineering. Mater Sci Eng: C (2016)

${ }^{39} \mathrm{H}$. Nojehdehian, F. Moztarzadeh, H. Baharvand, N. Zare Mehrjerdi, H. Nazarian, M. Tahriri. Int J Artif Organs, 33 (10) (2010), pp. 721-730.

${ }^{40} \mathrm{R}$. Yu, H. Chen, T. Chen, X. Zhou. Modeling and simulation of drug release from multi-layer biodegradable polymer microstructure in three dimensions. Simul Modell Pract Theory, 16 (1) (2008), pp. 15-25.

${ }^{41}$ A. Navaei, M. Rasoolian, A. Momeni, S. Emami, M. Rafienia. Double-walled microspheres loaded with meglumine antimoniate: preparation, characterization and in vitro release study. Drug Dev Ind Pharm, 40 (6) (2014), pp. 701-710.

${ }^{42}$ S.F.M. Salehi, F. Bastami, R. Tajerian. Fabrication and characterization of electrospun PLLA/collagen nanofibrous scaffold coated with chitosan to sustain release of aloe vera gel for skin tissue engineering. Biomed Eng: Appl Basis Commun, 28 (2016), pp. 1650035-1650043.

${ }^{43}$ F. Ghasemvand, E. Biazar, S. Tavakolifard, M. Khaledian, S. Rahmanzadeh, D. Momenzadeh, et al. Synthesis and evaluation of multi-wall carbon nanotube-paclitaxel complex as an anti-cancer agent. Gastroenterol Hepatol Bed Bench, 9 (3) (2016), p. 197.

${ }^{44} \mathrm{M}$. Tahriri, F. Moztarzadeh. Preparation, characterization, and in vitro biological evaluation of PLGA/nano-fluorohydroxyapatite (FHA) microsphere-sintered scaffolds for biomedical applications. Appl Biochem Biotechnol, 172 (5) (2014), pp. 2465-2479.

${ }^{45}$ U. Adhikari, N.P. Rijal, S. Khanal, D. Pai, J. Sankar, N. Bhattarai. Magnesium incorporated chitosan based scaffolds for tissue engineering applications. Bioact Mater, 1 (2) (2016), pp. 132-139.

${ }^{46}$ S. Sabudin, M. Derman, I. Zainol, K. Noorsal. In vitro cytotoxicity and cell seeding studies of a chitosan-silver composite for potential wound management applications. J Eng Sci, 8 (2012), pp. 29-37.

${ }^{47} \mathrm{H}$. Winter. Can the gel point of a cross-linking polymer be detected by the $\mathrm{G}^{\prime}-\mathrm{G}^{\prime \prime}$ crossover? Polym Eng Sci, 27 (22) (1987), pp. 1698-1702.

${ }^{48} \mathrm{H}$. Winter, F. Chambon, Rheol. 1986, 30, 367, CrossRef| CAS| Web of Science ${ }^{\circledR}$ Times Cited 1138.

${ }^{49} \mathrm{H}$. Henning Winter, Gel Point. Encyclopedia of polymer science and technology. John Wiley \& Sons, Inc (2002).

${ }^{50} \mathrm{~F}$. Tanaka. Polymer physics applications to molecular association and thermoreversible gelation. Cambridge University Press (2011).

${ }^{51} \mathrm{E}$. Leo, R. Cameroni, F. Forni. Dynamic dialysis for the drug release evaluation from doxorubicingelatin nanoparticle conjugates. Int J Pharm, 180 (1) (1999), pp. 23-30.

${ }^{52} \mathrm{~V}$. Singh, A. Chaudhary. Development and characterization of rosiglitazone loaded gelatin nanoparticles using two step desolvation method. Int J Pharm Sci Rev Res, 5 (2010), pp. 100103.

${ }^{53}$ K.K. Kim, D.W. Pack. Microspheres for drug delivery, BioMEMS and biomedical nanotechnology. Springer (2006), pp. 19-50.

${ }^{54} \mathrm{~F}$. Bastami. Letter to the Editor: critical-sized bone defect in sheep model. Bone, 68 (2014), p. 162.

55J. Rouwkema, J.D. Boer, C.A.V. Blitterswijk. Endothelial cells assemble into a 3-dimensional prevascular network in a bone tissue engineering construct. Tissue Eng, 12 (9) (2006), pp. 26852693. 
${ }^{56}$ Farshid Bastami, Zahra Sadat Paknejad, Maisa Jafari, Majid Salehi, Maryam Rezai Rad, A. Khojasteh. Fabrication of a three-dimensional $\beta$-tricalcium-phosphate/collagen containing chitosan-based nanoparticles for sustained release of bone morphogenetic protein-2: implication for bone tissue engineering. Mater Sci Eng: C, 72 (1) (2017), pp. 481-491.

${ }^{57}$ W. Schuurman, V. Khristov, M. Pot, P. Van Weeren, W. Dhert, J. Malda. Bioprinting of hybrid tissue constructs with tailorable mechanical properties. Biofabrication, 3 (2) (2011), p. 021001.

${ }^{58}$ B. Duan, L.A. Hockaday, K.H. Kang, J.T. Butcher. 3D bioprinting of heterogeneous aortic valve conduits with alginate/gelatin hydrogels. J Biomed Mater Res A, 101 (5) (2013), pp. 1255-1264.

${ }^{59}$ U. Rottensteiner, B. Sarker, D. Heusinger, D. Dafinova, S.N. Rath, J.P. Beier, et al. In vitro and in vivo biocompatibility of alginate dialdehyde/gelatin hydrogels with and without nanoscaled bioactive glass for bone tissue engineering applications. Materials, 7 (3) (2014), pp. 1957-1974.

${ }^{60}$ H.J. Kong, M.K. Smith, D.J. Mooney. Designing alginate hydrogels to maintain viability of immobilized cells. Biomaterials, 24 (22) (2003), pp. 4023-4029.

${ }^{61}$ A. Leal-Egaña, U.-D. Braumann, A. Díaz-Cuenca, M. Nowicki, A. Bader. Determination of pore size distribution at the cell-hydrogel interface. J Nanobiotechnol, 9 (1) (2011), p. 1.

${ }^{62}$ B. Sarker, R. Singh, R. Silva, J.A. Roether, J. Kaschta, R. Detsch, et al. Evaluation of fibroblasts adhesion and proliferation on alginate-gelatin crosslinked hydrogel. PLoS One, 9 (9) (2014), p. e107952.

${ }^{63}$ V. Komlev, N. Sergeeva, A.Y. Fedotov, I. Sviridova, V. Kirsanova, S. Akhmedova, et al. Investigation of physicochemical and biological properties of composite matrices in a alginate-calcium phosphate system intended for use in prototyping technologies during replacement of bone defects. Inorg Mater: Appl Res, 7 (4) (2016), pp. 630-634.

${ }^{64} \mathrm{~K}$. Alvarez, H. Nakajima. Metallic scaffolds for bone regeneration. Materials, 2 (3) (2009), pp. $790-832$.

${ }^{65}$ M.I. Gariboldi, S.M. Best. effect of ceramic scaffold architectural parameters on biological response. Front Bioeng Biotechnol, 3 (2015).

${ }^{66}$ M. Jafari, Z. Paknejad, M.R. Rad, S.R. Motamedian, M.J. Eghbal, N. Nadjmi, et al. Polymeric scaffolds in tissue engineering: a literature review. J Biomed Mater Res B Appl Biomater (2015).

${ }^{67}$ S. Tarafder, V.K. Balla, N.M. Davies, A. Bandyopadhyay, S. Bose. Microwave-sintered 3D printed tricalcium phosphate scaffolds for bone tissue engineering. J Tissue Eng Regen Med, 7 (8) (2013), pp. 631-641.

${ }^{68}$ P.V.F. Bastami, A. Khojasteh. The healing effects of platelet rich plasma on peripheral nerve injuries: a systematic review on in vivo studies. J Craniofac Surg, 28 (2017), pp. e49-357.

${ }^{69}$ X. Li, W. Yi, A. Jin, Y. Duan, S. Min. Effects of sequentially released BMP-2 and BMP-7 from PELA microcapsule-based scaffolds on the bone regeneration. Am J Transl Res, 7 (8) (2015), p. 1417.

${ }^{70}$ N. Davies, S. Dobner, D. Bezuidenhout, C. Schmidt, M. Beck, A.H. Zisch, et al. The dosage dependence of VEGF stimulation on scaffold neovascularisation. Biomaterials, 29 (26) (2008), pp. 3531-3538.

${ }^{71}$ F.R. Formiga, B. Pelacho, E. Garbayo, G. Abizanda, J.J. Gavira, T. Simon-Yarza, et al. Sustained release of VEGF through PLGA microparticles improves vasculogenesis and tissue remodeling in an acute myocardial ischemia-reperfusion model. J Control Release, 147 (1) (2010), pp. 30-37.

${ }^{72}$ N. Keramaris, G. Calori, V. Nikolaou, E. Schemitsch, P. Giannoudis. Fracture vascularity and bone healing: a systematic review of the role of VEGF. Injury, 39 (2008), pp. S45-S57.

${ }^{73}$ U. Mayr-Wohlfart, J. Waltenberger, H. Hausser, S. Kessler, K.-P. Günther, C. Dehio, et al. Vascular endothelial growth factor stimulates chemotactic migration of primary human osteoblasts. Bone, 30 (3) (2002), pp. 472-477.

${ }^{74}$ M. Orlandini, A. Spreafico, M. Bardelli, M. Rocchigiani, A. Salameh, S. Nucciotti, et al. Vascular endothelial growth factor-D activates VEGFR-3 expressed in osteoblasts inducing their differentiation. J Biol Chem, 281 (26) (2006), pp. 17961-17967. 
${ }^{75}$ P.C. Bessa, M. Casal, R. Reis. Bone morphogenetic proteins in tissue engineering: the road from laboratory to clinic, part II (BMP delivery). J Tissue Eng Regen Med, 2 (2-3) (2008), pp. 81-96.

${ }^{76}$ N.I. Zur Nieden, G. Kempka, H.J. Ahr. In vitro differentiation of embryonic stem cells into mineralized osteoblasts. Differentiation, 71 (1) (2003), pp. 18-27.

${ }^{77}$ E. Vorndran, U. Klammert, A. Ewald, J.E. Barralet, U. Gbureck. Simultaneous immobilization of bioactives during 3D powder printing of bioceramic drug-release matrices. Adv Funct Mater, 20 (10) (2010), pp. 1585-1591.

78J. Schnieders, U. Gbureck, E. Vorndran, M. Schossig, T. Kissel. The effect of porosity on drug release kinetics from vancomycin microsphere/calcium phosphate cement composites. J Biomed Mater Res B Appl Biomater, 99 (2) (2011), pp. 391-398.

${ }^{79}$ H.K. Makadia, S.J. Siegel. Poly lactic-co-glycolic acid (PLGA) as biodegradable controlled drug delivery carrier. Polymers, 3 (3) (2011), pp. 1377-1397.

${ }^{80} \mathrm{M}$. Ramchandani, D. Robinson. In vitro and in vivo release of ciprofloxacin from PLGA 50: 50 implants. J Control Release, 54 (2) (1998), pp. 167-175.

${ }^{81}$ N. Faisant, J. Siepmann, J. Benoit. PLGA-based microparticles: elucidation of mechanisms and a new, simple mathematical model quantifying drug release. Eur J Pharm Sci, 15 (4) (2002), pp. 355366.

${ }^{82}$ R. Masaeli, J. Kashi, T. Sadat, R. Dinarvand, M. Tahriri, V. Rakhshan, et al. Preparation, characterization and evaluation of drug release properties of simvastatin-loaded PLGA microspheres. Iranian J Pharm Res, 15 (2016), pp. 205-211. 